\title{
И.П. Макарова
}

\section{ВЗАИМОСВЯЗЬ ВНУТРЕННИХ СТРАХОВ И СМЫСЛОЖИЗЕННЫХ НАПРАВЛЕННОСТЕЙ ЛИЧНОСТИ В ПЕРИОД ЮНОШЕСТВА}

\begin{abstract}
Аннотация. В статье затрагиваются вопросы, связанные с внутренними страхами юношей и девушек двух возрастных периодов: старшего школьного возраста или ранней юности и поздней юности. Дается определение понятия "страх» и описывается классификация Ю. Щербатых. Рассматривается гипотеза о возможной взаимосвязи между внутренними страхами и смысложизненными направлениями у юношей и девушек, находящихся на разных возрастных этапах развития. Предмет исследования: переживание страха юношами и девушками на разных возрастных этапах с учетом выбора конкретного смысложизненного направления. Описываются методики, используемые в работе: "Опросник иерархической структуры актуальных страхов личности» (ИСАС) Ю. Щербатых и Е. Ивлевой, который позволяет определить интенсивность проявления разных видов страха и наличие фобий в целом; тест смысложизненных ориентаций СЖО Д.А. Леонтьева использовался в нашем исследовании с целью изучения смысложизненных и ценностных ориентаций юношей и девушек старшего икольного возраста и поздней юности. Полученные эмпирические данные с помощью методики "ИСАС» были прокоррелированы в каждой группе (3 группы школьников и 3 группы студентов с разным уровнем выраженности проявления страхов: высокий уровень выраженности страхов, средний и низкий уровни выраженности страхов) с показателями методики «Тест смысложизненных ориентаций» (СЖО) с применением критерия Пирсона. Формулируются выводы на базе проведенного исследования, подтверждающие гипотезу исследования и позволяющие говорить о динамике становления смысложизненных направлений в зависимости от уровня выраженности актуальных страхов личности.

Ключевые слова: психическое здоровье, трудности, требования, юноческий возраст, подростковый возраст, личность, смысложизненные направления, выраженность страха, страх, самореализация.
\end{abstract}

$\prod$ одростковый и юношеский возраст принято называть «переходным», так как это период больших перемен во внутренней жизни человека. Это период становления собственного «Я», формирования определенных социальных установок, а также поиск собственного места в жизни. Необходимо помнить, что в этот период развития человека появляется множество проблем, страхов и тревог, которые могут оказывать влияние на развитие и становление личности.

В отечественной психологии страх принято понимать, как «эмоцию, возникающую в ситуациях угрозы биологическому или социальному существованию индивида, и направленную на источник действительной или воображаемой опасности» ${ }^{1}$. То есть, страх основан на защитной реакции орга-

\footnotetext{
1 Краткий психологический словарь / Под ред. А.В. Петровского, М.Г. Ярошевского. М., 1985. С. 331.
}

низма, которая характеризуется интенсивностью и является обратимой «с возрастом», но при этом не затрагивает глубоко ценностные ориентации человека, а также существенно не влияет на его характер, поведение и взаимоотношения с окружающими людьми ${ }^{2}$. В своих исследованиях известный физиолог И.П. Павлов полагал, что страх - это проявление естественного рефлекса, имеющий оборонительную форму. Страх устроен на инстинкте самосохранения, носит остерегающий характер, и при этом происходят изменения высшей нервной деятельности, которые проявляется как учащенное дыхание, меняются показатели артериального давления ${ }^{3}$. Не-

\footnotetext{
2 Михеева Ю.В. Страх как психологическое состояние // Научное мнение: научный журнал. 2011. № 4.

3 Безденежных Б.Н. Физиология высшей нервной деятельности и сенсорных систем. Хрестоматия. Учебно-методический комплекс. М., 2012. 236 с.
} 


\section{Психология развития}

смотря на то, что страх выполняет защитную функцию, страх - любой - деструктивен для психики и эволюции человека ${ }^{4}$.

В настоящее время в отечественной и зарубежной психологии существует множество классификаций страхов. Одной из них является классификация Ю.В. Щербатых, который выделил три группы страхов: биологические, социальные и экзистенциальные. В группу биологических страхов входят страхи, связанные с угрозой жизни и здоровья человека. К социальным относятся страхи, связанные с изменением своего социального статуса. В третью группу входят страхи, связанные с глубинной сущностью человека, такие страхи характерны для всех людей ${ }^{5}$.

Ю.В. Щербатых делит экзистенциальные страхи на 4 группы:

1. страх перед пространством;

2. страх перед временем;

3. страх перед непознаваемостью жизни;

4. страх перед собой ${ }^{6}$.

Страх пространства один из часто встречающихся страхов, который содержит в себе следующие компоненты: страх замкнутого пространства, открытого пространства, высоты, глубины, и темноты. Один из самых сильных страхов - пространственный страх. Страх это вполне нормальное состояние, но остро выражающийся или навязчивый страх - это фобия. При этом отличить норму от патологии можно довольно условно. Симптомами страха принято считать дискомфорт в области груди, одышку, приступы тошноты, обильное потоотделение, дрожь в ногах, учащенный ритм сердца и другое. В свою очередь, страх перед временем может можно охарактеризовать как страх смерти или страх неизвестности будущего. Страх перед непознаваемостью жизни может проявляться в виде страха перед не пониманием окружающего мира и перед возможной бессмысленностью жизни. При этом страх перед собой заключается в непонимании себя, страхе своих возможных поступков или даже страхе сойти с ума.

\footnotetext{
4 Корнеенков С.С. Психодиагностика, психокоррекция и психотерапия субъективных переживаний страха в измененных состояниях сознания // NB: Психология и психотехника. 2013. № 4. С. 238-278.

5 Щербатых Ю.В., Ивлева Е.И. Психофизиологические и клинические аспекты страха, тревоги и фобий. Воронеж: Истоки, 1998.

6 Щербатых Ю.В. Избавься от страха. М.: ЭКСМО, 2010.
}

По мнению 3. Фрейда избавление от страха возможно только с помощью сублимации либидо, то есть направление потенциала личности в производственные и творческие цели ${ }^{7}$.

Для подростков эти страхи весьма актуальны, в связи с тем, что помимо изменений во внутреннем мире, общество предъявляет достаточно высокие требования к школьникам, которым необходимо не только успешно окончить общеобразовательное учреждение, но и выбирать будущую профессию, то есть, фактически определить свое дальнейшее место в жизни. Высокие требования, предъявляемые обществом, касаются и студентов, где правила высшего учебного заведения сами по себе являются строгими и требуют более высокого уровня ответственности и дисциплины со стороны обучающегося. Очень часто личность не готова быстро и успешно адаптироваться, что может быть связано со страхами и тревогами, берущими свое начало в детстве, либо обусловленными негативным прошлым опытом.

В связи с тем, что юношеский возраст можно охарактеризовать как период становления самосознания, самоопределения и самоутверждения, часто личность сталкивается с так называемым ценностным кризисом, преодоление которого затрудняется внутренними страхами ${ }^{8}$. Многие отечественные исследования говорят о том, что в условиях длительных кардинальных перемен, в новой социокультурной и политической ситуации, учащиеся юношеского возраста оказываются вынуждены с полной ответственностью осмысливать свой жизненный выбор и понимать его последствия, что во многом определяет будущее Российской Федерации ${ }^{9}$.

\footnotetext{
Акопян Л.С. Психолого-педагогическое исследование страхов детей младшего школьного возраста: Дис. ... канд. психол. наук. Самара, 2002; Орлов А.Б., Орлова Л.В., Орлова Н.А. Психологические механизмы возникновения и коррекции внушенных детских страхов // Вопросы психологии. 2011. № 3 C. 17-32.

8 Абдулгалимова С.В. Психологические особенности преодоления страха смерти у старшеклассников с разными смысложизненными стратегиями: Автореф. дис. ... канд. психол. наук. Ростов н/Д., 2010.

9 Кулагина И.Ю., Колюцкиий В.Н. Психология развития и возрастная психология. М.: Творческий центр, 2011. 237 с.; Сокальский Э.А. Юность - время пробы творческих сил и стартов в будущее // Вестник Московского государственного гуманитарного университета им. М.А. Шолохова. Педагогика и психология. 2013. № 2. С. 97-108.
} 
Существует множество факторов, влияющих на переживания внутренних страхов в подростковом и раннем юношеском возрастах. Одним из таких факторов является смысложизненная направленность личности, которая подразумевает наличие специфических личностных особенностей, конкретных ценностных ориентаций человека, отношение к жизни в целом и другое. Поэтому, изучение особенностей переживания внутренних страхов на этом этапе позволит наиболее ярко показать специфику взаимосвязи переживания страха и смысложизненной направленности личности. Таким образом, целью нашего исследования выступает анализ взаимосвязей между внутренними страхами и смысложизненной направленностью у юношей и девушек на разных возрастных этапах. Объектом исследования являются юноши и девушки, представители двух возрастных категорий. Первая группа характеризуется возрастным цензом от 15 до 17 лет и соответствует возрастному этапу старшего школьного возраста или ранней юности. Респонденты первой группы являются учениками старших классов городской гимназии г. Ростова-на-Дону. Вторую группу респондентов составили студенты третьего курса университета г. Ростова-на-Дону, учащиеся факультета психологии и физики в возрасте от 20 до 21 года, который соотносится с возрастным этапом поздней юности или ранней зрелости. Всего в исследовании приняли участие 362 школьника и студента. Первая группа включила в себя 110 девушек-школьниц и 120 юношей-школьников. Вторая группа респондентов насчитывает 70 девушек-студенток и 62 юношей-студентов.

В качестве гипотезы исследования нами было выдвинуто следующее предположение: «Существует взаимосвязь между внутренними страхами и смысложизненными направленностями у юношей и девушек, что обусловлено разными возрастными этапами развития личности».

В работе были использованы следующие методики, направленные на изучение уровня выраженности и интенсивности проявления внутренних страхов у юношей и девушек на разных возрастных этапах жизнедеятельности: Опросник иерархической структуры актуальных страхов личности» (ИСАС) Ю. Щербатых и Е. Ивлевой ${ }^{10}$. Опросник по-

10 Щербатых Ю.В., Ивлева Е.И. Психофизиологические и клинические аспекты страха, тревоги и фобий. Воронеж: Истоки, 1998. зволяет определить интенсивность проявления разных видов страха и наличие фобий в целом; тест смысложизненных ориентаций СЖО Д.А. Леонтьева использовался в нашем исследовании с целью изучения смысложизненных и ценностных ориентаций юношей и девушек старшего школьного возраста и поздней юности ${ }^{11}$. Тест состоит из общего показателя осмысленности жизни и пяти субшкал, отражающих три конкретные смысложизненные ориентации и два аспекта локуса контроля, а именно: цели в жизни, процесс жизни или интерес и эмоциональная насыщенность жизни, результативность жизни или удовлетворенность самореализацией, локус контроля - Я, локус контроля - жизнь или управляемость жизни. Надежность полученных данных обеспечивается достаточным объемом эмпирической выборки, тщательным качественным анализом данных, а также использованием следующих методов математической статистики: анализ и вычисление стандартного отклонения от среднего значения для определения групп с разным уровнем выраженности проявления страха; коэффициент корреляции Пирсона, для выявления связи между переменными.

Основываясь на теоретическом обосновании взаимосвязи уровня выраженности различных внутренних страхов и смысложизненных направленностей юношей и девушек разного возраста, мы предприняли попытку эмпирически показать эту взаимосвязь. Нами было проведено исследование, посвященное изучению связи между уровнем выраженности и интенсивности проявления внутреннего страха и выбором смысложизненного направленностей. С этой целью были получены данные на большой выборке респондентов (362 человек) по всем методикам. Полученные эмпирические данные с помощью методики «ИСАС» были прокоррелированы в каждой группе (3 группы школьников и 3 группы студентов с разным уровнем выраженности проявления страхов: высокий уровень выраженности страхов, средний и низкий уровни выраженности страхов) с показателями методики «Тест смысложизненных ориентаций» (СЖО) с применением критерия Пирсона.

Результаты, полученные в ходе соответствующих статистических процедур, позволяют утверждать, что у представителей группы с высоким уровнем выраженности этого феномена наблюда-

11 Леонтьев Д.А. Тест смысложизненных ориентации (СЖО). 2-е изд. М.: Смысл, 2000. 


\section{Психология развития}

ется низкий уровень понимания общей осмысленности жизни, неудовлетворенность результатами собственной деятельности, что на наш взгляд обусловлено низкой успеваемостью в обучении и трудностями межличностного взаимодействия со сверстниками, а также респонденты испытывают недостаток эмоциональной насыщенности в повседневной жизни, что в свою очередь указывает на отсутствие интереса к тому или иному виду деятельности в целом. Согласно результатам исследования, высокий уровень выраженности проявления и интенсивности актуальных страхов подростков способствует возникновению ряда трудностей на пути к развитию социальной компетентности в этом возрасте и препятствует формированию конструктивной смысложизненной направленности. Этот факт подтверждается в исследованиях И.В. Калинина и указывает на необходимость коррекционной и профилактической работы с актуальными страхами девочек и мальчиков старшего школьного возраста ${ }^{12}$.

При анализе корреляционных связей для всей выборки обнаружена отрицательная зависимость между актуальными страхами личности школьника и смысложизненной направленностью «Эмоциональная насыщенность жизни» $(\mathrm{r}=-0,4)$. Выявленная связь демонстрирует затруднение выражения таких эмоциональных состояний как радость, печаль и т.д. у старших школьников в том случае, если они испытывают страх. Далее, обнаружена значимая отрицательная связь между актуальными страхами личности школьника и смысложизненной направленностью «Результативность жизни» (r=-0,4). Связь свидетельствует о трудностях самовыражения школьников с высоким уровнем выраженности внутренних страхов, а также об отсутствии удовлетворенности собственной жизнью. Затем, обнаружена отрицательная значимая корреляционная связь между актуальными страхами личности школьника и смысложизненной направленностью «Общая осмысленность жизни» $(\mathrm{r}=-0,4)$. Осмысленность жизни характеризуется представлениями школьника не только о собственных способностях и применении их в реальной жизни, но и постановкой жизненных целей. Поэтому выявленная связь

\footnotetext{
12 Калинин И.В. Осмысленность жизни как показатель социальной компетентности в юношеском возрасте // Социальная компетентность детей и подростков: тенденции формирования. СВНЦ. 2002. С. 55-62.
}

позволяет говорить о деструктивном характере страха и неспособности школьников действовать уверенно при принятии важных решений, которые могут повлиять на весь жизненный путь человека (например, выбор профессии).

Далее нами была рассмотрена группа школьников с низким уровнем проявления страха, которая составляет 10,3 \% респондентов от общей выборки. Результаты, полученные в ходе соответствующих статистических процедур, позволяют утверждать, что у представителей группы с низким уровнем выраженности проявления страха наблюдается ясное понимание жизненных целей и собственных стремлений к социальному благополучию, умеренная удовлетворенность собственной деятельностью и высокий уровень осмысленности жизни в целом, что подразумевает адекватную оценку собственных сил при достижении поставленных целей. При анализе корреляционных связей для всей выборки обнаружена высокозначимая отрицательная корреляционная связь между актуальными страхами личности школьника и смысложизненной направленностью «Цели в жизни» $(r=-0,6)$. Выявленная связь указывает на отсутствие у данной группы испытуемых проблем, связанных с целеполаганием, которое может быть обусловлено внутренними страхами. Также, была обнаружена отрицательная значимая корреляционная связь между актуальными страхами личности школьника и смысложизненной направленностью «Результативность жизни» (r=-0,3). Данная связь в группе школьников с низким уровнем выраженности проявления страха позволяет говорить о выраженном стремлении испытуемых к саморазвитию и о конструктивной самокритике на пути к самореализации. Таким образом, школьники испытывают скорее тревожность или волнение при достижении поставленных жизненных целей, но при этом уверены в собственных силах. Затем, нами было обнаружено, что школьники с низким уровнем проявления страха склонны к практическому осмыслению всех сторон жизни, базовых личных ценностей и ценностей современного общества. Это подтверждается наличием высокозначимой отрицательной корреляционной связи между актуальными страхами личности школьника и смысложизненной направленностью «Общая осмысленность жизни» $(r=-0,5)$. Низкий уровень проявления страха позволяет подростку познавать мир с интересом и любознательностью, проявляя такие личностные качества как опти- 
мизм, активность, инициативность, а также стремление проявить собственную индивидуальность и многое другое.

Рассмотрим третью группу школьников - со средним уровнем проявления страха, которая составляет 75,9\% респондентов от общей выборки. Согласно результатам исследования, уровень проявления страха обусловливает взаимодействие некоторых личностных характеристик школьников, а именно способность к самоуправлению, уровень эмоционального интеллекта и адекватную самооценку. Совокупность указанных характеристик и уровень проявления страха определяет смысложизненную направленность личности школьника. В группе респондентов со средним уровнем страха доминируют такие направления, как «Жизненный процесс», «Локус-контроля Я» и «Локус-контроля жизнь». При анализе корреляционных связей для всей выборки обнаружена высокозначимая отрицательная связь между актуальными страхами личности школьника и смысложизненной направленностью «Эмоциональная насыщенность жизни» $(\mathrm{r}=-0,4)$. Выявленная связь свидетельствует о том, что респонденты принимают решения осторожно, основываясь на прошлом опыте. Процесс целеполагания в данном случае обусловлен требованиями общества или желаниями старшего поколения. Школьники старшего возраста со средним уровнем выраженности проявления страха в ряде случаев дозируют собственные эмоциональные всплески, предпочитая размеренную, спланированную жизнь. Затем, нами была обнаружена высокозначимая отрицательная связь между актуальными страхами личности школьника и смысложизненной направленностью «Локус-контроля Я» $(\mathrm{r}=-0,5)$. Локус контроля Я как личностное свойство предполагает свободу выбора и определенный уровень ответственности, а также выражается в доверии человека к самому себе. Поэтому, данная связь указывает нам на тот факт, что несмотря на страхи, которые могут воздействовать на личность старшего школьника, респонденты готовы выстраивать свою жизненную линию в соответствии именно со своими представлениями о ее целях и смысле. Также была выявлена отрицательная значимая корреляционная связь между актуальными страхами личности школьника и смысложизненной направленностью «Локус-контроля жизнь» $(\mathrm{r}=-0,5)$. Связь характеризует респондентов частичным отсутствием свободы в принятии решений, а также скромностью в отстаивании соб- ственной жизненной позиции. Актуальные страхи в данной группе сводятся к бытовым проблемам и детско-родительским отношениям, когда школьники еще не имеют полноправной возможности принимать решения и испытывают страх воплощать свои желания в реальность.

В задачи нашего исследования входит сравнительный анализ групп респондентов разного возраста. В этой связи мы аналогичным образом изучили взаимосвязь актуальных страхов личности и выбора смысложизненной направленности у респондентов, находящихся на возрастном этапе поздней юности или ранней зрелости. Проведенное исследование позволяет утверждать, что существует динамика смысложизненных ориентаций в процессе образования и становления личности. Такая динамика прослеживается в эмоциональной окрашенности жизни, способах самореализации личности и в осмыслении бытия в целом.

Рассмотрим группу респондентов-студентов с высоким уровнем проявления страха. Результаты, полученные в ходе соответствующих статистических процедур, указывают на тот факт, что студенты с высоким уровнем страха выбирают такие смысложизненные направленности как «Локусконтроля Я». Это подтверждается положительной значимой корреляционной связью между актуальными страхами личности и смысложизненной направленностью «Локус-контроля Я» $(\mathrm{r}=0,4)$. Учитывая, что на этом этапе развития респонденты сталкиваются с определенными обязанностями, которые связаны с получением высшего профессионального образования, они испытывают специфические виды страха, обусловленные предъявляемыми требованиями общества, что в свою очередь способствует повышенному уровню ответственности. В связи с этим, страх является своеобразным мотивом достижения жизненной цели. В данной группе была выявлена отрицательная значимая корреляционная связь между страхами личности и смысложизненной направленностью «Жизненный процесс» $(\mathrm{r}=-0,3)$. Такая связь свидетельствует о том, что находясь в ситуации неопределенности или повышенной тревожности, личность сдерживает эмоциональные проявления, опасаясь негативно повлиять на сложившиеся обстоятельства. Следует отметить, что по сравнению с респондентами-школьниками у студентов связь выражена слабее, что позволяет говорить о положительной динамике жизненного процесса. Также была установлена отрицательная значимая кор- 


\section{Психология развития}

реляционная связь между актуальными страхами личности и смысложизненной направленностью «Результативность жизни» $(\mathrm{r}=-0,3)$. Таким образом, респонденты с высоким уровнем проявления страха нуждаются в положительной оценке своей деятельности со стороны, только в этом случае они смогут испытать чувство радости и удовлетворенность от собственных достижений.

Далее рассмотрим группу студентов с низким уровнем проявления страха, которая составляет $18,8 \%$ респондентов от общей выборки. Полученные результаты, позволяют утверждать, что у представителей группы с низким уровнем выраженности проявления страха наблюдается тенденция к следующей совокупности смысложизненных направленностей: «Общая осмысленность жизни» и «Локус контроля - жизнь». Выявленные связи являются отрицательными и высокозначимыми $(\mathrm{r}=-0,5)$ и $(\mathrm{r}=-0,4)$. Следовательно, студенты младших курсов осознают значимость своей деятельности и, испытывая дискомфорт или тревожность, противостоят этому чувству посредством усиленного самоконтроля. К контролю в данном случае можно отнести развитие таких личностных характеристик, как пунктуальность, дисциплинированность, ответственность, прилежность и т.д. Важно понимать, что в отличие от школьников, студенты с низким уровнем проявления страха имеют преимущество свободы принятия решений, которое позволяет им наиболее ярче понимать бытие и ценность жизни.

Затем проанализируем результаты группы респондентов со средним уровнем выраженности страха, 66,7 \% респондентов от общей выборки. Полученные результаты указывают на трудности, которые испытывают студенты со средним уровнем страха при построении собственной жизни в соответствии с представлениями о ее смысле и ценности. В этом случае страх можно охарактеризовать, как своеобразный толчок на пути к достижению цели. Это подтверждается выявленной положительной значимой корреляционной связью между страхами личности и смысложизненной направленностью «Локус-контроля Я» $(\mathrm{r}=0,4)$. Так же нами были выявлены отрицательные связи между страхами студентов и такими смысложизненными направленностями как «Жизненный процесс» и «Результативность жизни» $(\mathrm{r}=-0,3)$ и $(\mathrm{r}=-0,4)$. Таким образом, средний уровень выраженности страхов респондентов оказывает прямое воздействие на эмоциональную насыщенность всего жизненного процесса и на эффективность их деятельности. При этом, респонденты понимают, что им есть к чему стремиться и пройденные этапы жизни воспринимают как необходимый опыт для достижения глобальных жизненных целей.

Таким образом, опираясь на результаты исследования, можно говорить о динамике становления смысложизненных направленностей в зависимости от уровня выраженности актуальных страхов личности. Результаты исследования определяют круг проблем, связанных с выбором жизненной ориентации, что обусловлено уровнем выраженности внутренних страхов личности. В этой связи, мы видим необходимость профилактической и коррекционной работы с участниками исследования, которая поможет им осознать внутренний страх, и справится с ним посредством целеполагания и понимания собственных жизненных целей. Таким образом, выбор комплекса жизненных ориентаций, вне зависимости от уровня проявления внутренних страхов в условиях современных жестких требований, которые предъявляются к молодому поколению, не только служит признаком психического здоровья и зрелости личности, но и является гарантом последующего полноценного существования человека.

\section{Список литературы:}

1. Абдулгалимова С.В. Психологические особенности преодоления страха смерти у старшеклассников с разными смысложизненными стратегиями: Автореф. дис. ... канд. психол. наук. Ростов н/Д., 2010.

2. Акопян Л.С. Психолого-педагогическое исследование страхов детей младшего школьного возраста: Дис. ... канд. психол. наук. Самара, 2002.

3. Безденежных Б.Н. Физиология высшей нервной деятельности и сенсорных систем. Хрестоматия. Учебно-методический комплекс. М., 2012. 236 с.

4. Калинин И.В. Осмысленность жизни как показатель социальной компетентности в юношеском возрасте // Социальная компетентность детей и подростков: тенденции формирования. СВНЦ. 2002. С. 55-62.

5. Корнеенков С.С. Психодиагностика, психокоррекция и психотерапия субъективных переживаний страха в измененных состояниях сознания // NB: Психология и психотехника. 2013. № 4. С. 238-278.

6. Краткий психологический словарь / Под ред. А.В. Петровского, М.Г. Ярошевского. М., 1985.

7. Кулагина И.Ю., Колюцкий В.Н. Психология развития и возрастная психология. М.: Творческий центр, 2011.237 с. 


\section{Психология и психотехника 10(73) • 2014}

8. Леонтьев Д.А. Тест смысложизненных ориентации (СЖО). 2-е изд. М.: Смысл, 2000.

9. Михеева Ю.В. Страх как психологическое состояние // Научное мнение: научный журнал. 2011 . № 4.

10. Орлов А.Б., Орлова Л.В., Орлова Н.А. Психологические механизмы возникновения и коррекции внушенных детских страхов // Вопросы психологии. 2011. № 3 С. 17-32.

11. Сокальский Э.А. Юность - время пробы творческих сил и стартов в будущее // Вестник Московского государственного гуманитарного университета им. М.А. Шолохова. Педагогика и психология. 2013. № 2. С. 97-108.

12. Щербатых Ю.В. Избавься от страха. М.: ЭКСМО, 2010.

13. Щербатых Ю.В., Ивлева Е.И. Психофизиологические и клинические аспекты страха, тревоги и фобий. Воронеж: Истоки, 1998.

\section{References (transliteration):}

1. Abdulgalimova S.V. Psikhologicheskie osobennosti preodoleniya strakha smerti u starsheklassnikov s raznymi smyslozhiznennymi strategiyami: Avtoref. dis. ... kand. psikhol. nauk. Rostov n/D., 2010.

2. Akopyan L.S. Psikhologo-pedagogicheskoe issledovanie strakhov detei mladshego shkol'nogo vozrasta: Dis. ... kand. psikhol. nauk. Samara, 2002.

3. Bezdenezhnykh B.N. Fiziologiya vysshei nervnoi deyatel'nosti i sensornykh sistem. Khrestomatiya. Uchebno-metodicheskii kompleks. M., 2012. $236 \mathrm{~s}$.

4. Kalinin I.V. Osmyslennost' zhizni kak pokazatel' sotsial'noi kompetentnosti v yunosheskom vozraste // Sotsial'naya kompetentnost' detei i podrostkov: tendentsii formirovaniya. SVNTs. 2002. S. 55-62.

5. Korneenkov S.S. Psikhodiagnostika, psikhokorrektsiya i psikhoterapiya sub"ektivnykh perezhivanii strakha v izmenennykh sostoyaniyakh soznaniya // NB: Psikhologiya i psikhotekhnika. 2013. № 4. C. 238-278.

6. Kratkii psikhologicheskii slovar' / Pod red. A.V. Petrovskogo, M.G. Yaroshevskogo. M., 1985.

7. Kulagina I.Yu., Kolyutskiı̌ V.N. Psikhologiya razvitiya i vozrastnaya psikhologiya. M.: Tvorcheskii tsentr, 2011.237 s.

8. Leont'ev D.A. Test smyslozhiznennykh orientatsii (SZhO). 2-e izd. M.: Smysl, 2000.

9. Mikheeva Yu.V. Strakh kak psikhologicheskoe sostoyanie // Nauchnoe mnenie: nauchnyı̆ zhurnal. 2011 . № 4.

10. Orlov A.B., Orlova L.V., Orlova N.A. Psikhologicheskie mekhanizmy vozniknoveniya i korrektsii vnushennykh detskikh strakhov // Voprosy psikhologii. 2011. № 3. S. 17-32.

11. Sokal'skii E.A. Yunost' - vremya proby tvorcheskikh sil i startov v budushchee // Vestnik Moskovskogo gosudarstvennogo gumanitarnogo universiteta im. M.A. Sholokhova. Pedagogika i psikhologiya. 2013. № 2. S. 97-108.

12. Shcherbatykh Yu.V. Izbav'sya ot strakha. M.: EKSMO, 2010.

13. Shcherbatykh Yu.V., Ivleva E.I. «Psikhofiziologicheskie i klinicheskie aspekty strakha, trevogi i fobii». Voronezh: Istoki, 1998. 